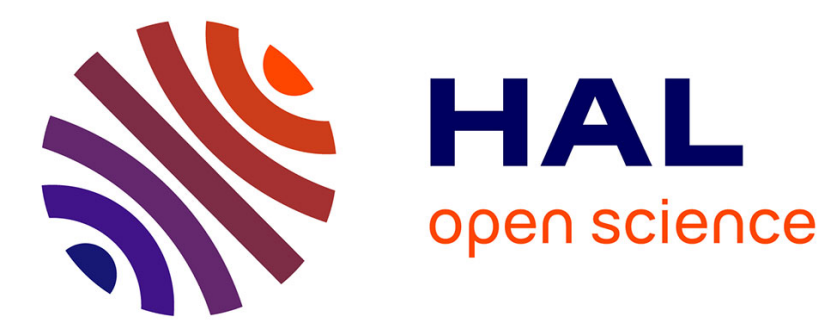

\title{
Numerical study of gaseous reactive flow over a ram accelerator projectile in subdetonative velocity regime
}

\author{
T. Bengherbia, Y. F. Yao, P. Bauer, C. Knowlen
}

\section{To cite this version:}

T. Bengherbia, Y. F. Yao, P. Bauer, C. Knowlen. Numerical study of gaseous reactive flow over a ram accelerator projectile in subdetonative velocity regime. European Physical Journal: Applied Physics, 2011, 55 (1), 10.1051/epjap/2011100087 . hal-00719811

\section{HAL Id: hal-00719811 \\ https://hal.science/hal-00719811}

Submitted on 21 Jul 2012

HAL is a multi-disciplinary open access archive for the deposit and dissemination of scientific research documents, whether they are published or not. The documents may come from teaching and research institutions in France or abroad, or from public or private research centers.
L'archive ouverte pluridisciplinaire HAL, est destinée au dépôt et à la diffusion de documents scientifiques de niveau recherche, publiés ou non, émanant des établissements d'enseignement et de recherche français ou étrangers, des laboratoires publics ou privés. 


\title{
Numerical study of gaseous reactive flow over a ram accelerator projectile in subdetonative velocity regime
}

\author{
T. Bengherbia ${ }^{1,2, a}$, Y.F. Yao ${ }^{2, b}$, P. Bauer ${ }^{1, c}$, and C. Knowlen ${ }^{3, d}$ \\ ${ }^{1}$ Laboratoire de Combustion et de Détonique (CNRS), ENSMA Poitiers, BP 109, 86960 Futuroscope Cedex, France \\ 2 Faculty of Engineering, Kingston University, Roehampton Vale, Friars Avenue, London SW15 3DW, UK \\ 3 Department of Aeronautics and Astronautics, University of Washington, Box 352400, Seattle, WA 98195-2400, USA
}

Received: date / Revised version: date

\begin{abstract}
Computational fluid dynamics solutions of the Reynolds Averaged Navier-Stokes equations have been used to numerically predict the thrust in the thermally choked ram accelerator propulsive mode. Studies were focused on a projectile operating in a 38-mm-diameter ram accelerator tube loaded with premixed propellant gas; methane/oxygen/nitrogen at 5.15 MPa fill pressure. Simulations were carried out for a series of incoming velocities. The shear-stress transport turbulence model (SST) and the eddy dissipation combustion model (EDM) with five-step reaction mechanism were used to simulate the fully turbulent reactive flow field around the projectile. The predicted projectile thrust-velocity agreed well a with the experimental measurements, in addition, the CFD predicted pressure variation and magnitude along projectile axial direction also agreed well with the test data. The present investigation reveals some key features of the shock system around the projectile, which are important in determining the characteristics of the thermally choked propulsive mode. These findings are useful in understanding the characteristics of high speed turbulent combustion process in the ram accelerator.
\end{abstract}

PACS. 47.40.-x Compressible flows; shock waves; 47.70.Fw Chemically reactive flows; 47.70.Pq Flames; combustion

\section{Introduction}

The ram accelerator is a propulsion concept for accelerating projectiles to very high velocities [1]. Its fundamental principle is to use shock-induced turbulent combustion to generate high thrust levels for projectile propulsion. In the ram accelerator, the projectile travels at supersonic speeds in a launch tube filled with premixed fuel-oxidizer gas mixtures, generating a complex shock wave system in the flow passage between the projectile body and the tube wall. At the start of the launch process combustion is initiated at the base of the projectile. The heat release from combustion thermally chokes the flow behind the projectile at velocities below the Chapman-Jouguet (C-J) detonation speed of the propellant, as shown in Fig. 1, which maintains high projectile base pressure. The projectile is thus accelerated by the resulting differential pressure until it reaches the C-J detonation speed of the propellant, which can exceed $3000 \mathrm{~m} / \mathrm{s}$. Previous experimental investigations $[2,3]$ have shown that the ram accelerator operating characteristics are dependent on the in-tube Mach num-

\footnotetext{
a email: tarek.bengherbia@lcd.ensma.fr

b email: y.yao@kingston.ac.uk

c email: bauer@lcd.ensma.fr

d email: knowlen@aa.washington.edu
}

ber, propellant composition, and flow velocity relative to the C-J detonation speed.

Numerous experimental investigations of the subdetonative velocity regime have been carried out at Mach numbers ranging from 2.5 to 5 [4-8]. The supersonic incoming flow is compressed by reflected shock waves in the contraction area of the conical forebody and rendered subsonic by a normal shock wave system on the tapered aftbody of the projectile. The subsonic combustion is nominally stabilized by the bluff projectile base acting as a flame-holder and the heat release subsequently thermally chokes the entire flow area downstream. As the projectile increases its velocity, the increased flow temperature reduces the chemical ignition delay time and enhances the flame speed so that the combustion process moves upstream and eventually up on to the projectile body.

In principle, inviscid flow models can be used to predict the approximate position of the normal shock-wave and thus determine theoretical bounds of thermally choked ram accelerator operation [1,2]. Earlier studies based on one-dimensional modeling have confirmed that the projectile acceleration and thermally choked pressure can be estimated with fairly good agreement with available test 


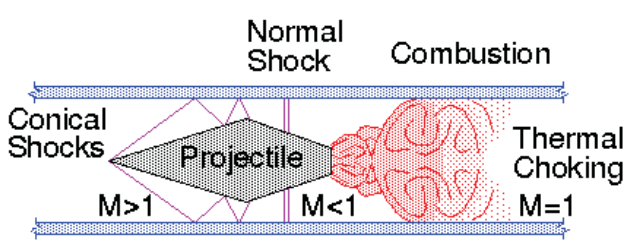

Fig. 1. The flow features in thermally choked ram accelerator propulsive mode

data $[2,9]$. Different kinetic reaction mechanism (e.g. global one-step reaction, two-step and five-step reactions) were used to simulate the combustion process in the ram accelerator [10-13]. It was found that the predictions from three reaction models are broadly quite similar up to the projectile trailing-edge, after that in the wake region, some significant differences appear, of which the one-step reaction model over-predicts the pressure in the flow field behind the projectile base, and the two-step reaction model under-predicts the pressure in the near field behind the projectile. Among the three models tested, the results of the five-step reaction model are in better agreement with experimental data in both the near and far fields.

The purpose of this study is to examine in detail the flow field characteristics of the thermally choked ram accelerator using a five-step kinetic reaction mechanism and to validate the modeling with data from a representative experiment at the University of Washington 38-mmdiameter ram accelerator facility. The Reynolds Averaged Navier-Stokes equations are solved together with Menter's shear stress transport (SST) turbulence model [14] for viscous flow prediction, and the Eddy Dissipation combustion Model (EDM) [15-17] was used to simulate the reactive flow field around the projectile. The ram accelerator test data used for comparison, comes from a 16-m-long tube experiment filled with $2.95 \mathrm{CH}_{4}+2 \mathrm{O}_{2}+5.7 \mathrm{~N}_{2}$ propellant at $5.15 \mathrm{MPa}$ with a titanium alloy projectile having a mass of $109 \mathrm{~g}$. In this experiment, the projectile entered the test section at $1060 \mathrm{~m} / \mathrm{s}$ and accelerated throughout its length to exit at $2050 \mathrm{~m} / \mathrm{s}$.

\section{Steady RANS Combustion Modeling}

One of the main challenges in combustion/turbulence modeling and shock-wave/boundary layer interaction is the accurate prediction of flow separation from a smooth surface. Standard two-equation turbulence models often fail to predict the onset and the extent of flow separation under adverse pressure gradient conditions. This is an important phenomenon in the ram accelerator. In fact, it is one of the regions where ignition of the propellant often occurs and these separation bubbles act as flame holders. The most prominent two-equation models in this area is the Menter's SST model [14], which was designed to give more accurate predictions of the onset and the amount of flow separation under adverse pressure gradients by the inclusion of transport effects into the formulation of the turbulent eddy-viscosity. This results in a major improvement in terms of flow separation predictions.

Because the flow field in the combustion region behind the projectile is assumed to be fully turbulent, we opted for the Eddy Dissipation concept of Magnussen [15-17]. The Eddy Dissipation model is better applied to turbulent flows when the chemical reaction rate is fast, compared to the transport processes in the flow (i.e. high Damköhler number, $D_{a}=\tau_{t} / \tau_{c}$ ), and both the fuel and oxidant are available in the control volume for the combustion to occur. Here the typical eddy life time $\tau_{t}$ and the chemical reaction induction time $\tau_{c}$ depend on the fluid pressure and temperature. The Eddy Dissipation model assumes that the chemical reaction rate is related directly to the time required to mix reactants at the molecular level. In turbulent flows, $\tau_{t}$ is dominated by the eddy properties, and therefore the reaction rate is proportional to a mixing time scale defined by the turbulence kinetic energy $k$ and the turbulence dissipation rate $\varepsilon$. The characteristic eddy length scale is defined as $l=k^{3 / 2} / \varepsilon$.

\section{Governing equations}

The governing equations for the chemically reacting viscous flows are the compressible Navier-Stokes equations with chemical source terms for a mixture composed of $N$ gas species, which are expressed in the following form:

$$
\frac{\partial Q}{\partial t}+\frac{\partial E}{\partial x}+\frac{\partial F}{\partial y}=\frac{\partial E_{v}}{\partial x}+\frac{\partial F_{v}}{\partial y}+H+H_{v}+S
$$

where

$$
Q=\left[\rho_{1}, \ldots \rho_{N}, \rho u, \rho v, \rho e\right]^{T}
$$

$$
E=\left[\rho_{1} u, \ldots, \rho_{N} u, \rho u^{2}+p, \rho u v, u(\rho e+p)\right]^{T},
$$

$$
F=\left[\rho_{1} v, \ldots, \rho_{N} v, \rho u v, \rho v^{2}+p, v(\rho e+p)\right]^{T}
$$

$$
\begin{gathered}
E_{v}=\left[\rho_{1} D_{1} \frac{\partial c_{1}}{\partial x}, \ldots, \rho_{N} D_{N} \frac{c_{N}}{\partial x}, \tau_{x x},\right. \\
\left.\tau_{x y}, u \tau_{x x}+v \tau_{x y}+q_{x}\right]^{T} \\
F_{v}=\left[\rho_{1} D_{1} \frac{\partial c_{1}}{\partial y}, \ldots, \rho_{N} D_{N} \frac{\partial c_{N}}{\partial y}, \tau_{x y},\right. \\
\left.\tau_{y y}, u \tau_{x y}+v \tau_{y y}+q_{y}\right]^{T} \\
H=-\frac{m}{y}\left[\rho_{1} v, \ldots, \rho_{N} v, \rho u v, \rho v^{2}, v(\rho e+p)\right]^{T} \\
H_{v}=-\frac{m}{y}\left[\rho_{1} D_{1} \frac{\partial c_{1}}{\partial y}, \ldots, \rho_{N} D_{N} \frac{\partial c_{N}}{\partial y}, \tau_{x y},\right.
\end{gathered}
$$




$$
\begin{gathered}
\left.\tau_{y y}-\tau_{\theta \theta}, u \tau_{x y}+v \tau_{y y}+q_{y}\right]^{T}, \\
S=\left[\dot{\omega}_{1}, \ldots, \dot{\omega}_{N}, 0,0,0\right]^{T},
\end{gathered}
$$

where the transpose of a matrix is defined by the operator $T$, and shear stresses and heat fluxes are defined as

$$
\begin{gathered}
\tau_{x x}=2 \mu \frac{\partial u}{\partial x}-\frac{2}{3} \mu \nabla \cdot \mathbf{u}-\frac{m v}{y}=\frac{2}{3} \mu\left(2 \frac{\partial u}{\partial x}-\frac{\partial v}{\partial y}-\frac{m v}{y}\right) \\
\tau_{y y}=2 \mu \frac{\partial v}{\partial y}-\frac{2}{3} \mu \nabla \cdot \mathbf{u}-\frac{m v}{y}=\frac{2}{3} \mu\left(2 \frac{\partial v}{\partial y}-\frac{\partial u}{\partial x}-\frac{m v}{y}\right), \\
\tau_{x y}=\mu\left(\frac{\partial u}{\partial y}-\frac{\partial v}{\partial x}\right) \\
\tau_{\theta \theta}=2 \mu \frac{v}{y}-\frac{2}{3} \mu \nabla \cdot \mathbf{u} \\
q_{x}=\lambda \frac{\partial T}{\partial x}+\rho \sum_{k=1}^{N} D_{k} h_{k} \frac{\partial c_{k}}{\partial x} \\
q_{y}=\lambda \frac{\partial T}{\partial y}+\rho \sum_{k=1}^{N} D_{k} h_{k} \frac{\partial c_{k}}{\partial y} .
\end{gathered}
$$

The equations describe a two-dimensional plane flow if $\mathrm{m}$ $=0$ and axisymmetric flow if $\mathrm{m}=1 . u$ and $v$ are velocity components, $p$ is the pressure, $T$ is the temperature, $e$ is the total energy per unit mass, $\rho_{k}$ is the density of species $k$, with total density $\rho=\sum_{k=1}^{N} \rho_{k}, c_{k}=\frac{\rho_{k}}{\rho}$ is the mass fraction, $\dot{\omega}_{k}$ is the mass production rate of species $k$ due to chemical reactions, $h_{k}$ is the specific enthalpy, $D_{k}$ is the mass diffusivity of species $k$ in the mixture defined as

$$
D_{k}=\left(1-X_{k}\right) / \sum_{j \neq k} \frac{X_{j}}{D_{k j}}
$$

where $D_{k j}$ is the binary diffusivity, $X_{k}$ is the mole fraction, and $\mu$ is the viscosity, $\lambda$ is conductivity of the gas mixture, respectively. The diffusive transport coefficient, $\nu$ and $\lambda$ can be determined using Wilke's semi-empirical formula with $\nu_{k}$ and $\lambda_{k}$ of each species found from NASA thermodynamic data [18]. For high speed flow simulations, mass diffusion can be greatly simplified by neglecting pressure diffusion and thermal diffusion, and assuming the binary diffusivity $D_{k j}$ to be equal between all components. Its value is obtained by assuming a constant Schmidt number $S_{c}=\mu /\left(\rho D_{k j}\right)$. It is assumed that all species are thermally perfect, in thermal equilibrium and have the same temperature. The equation of state for a mixture of thermally perfect gases is:

$$
p=\sum_{k=1}^{N} \frac{\rho_{k}}{M_{k}} R T
$$

where $M_{k}$ is the molecular weight of species $k$ and $R$ is the universal gas constant. The total energy per unit volume $\rho e$ is used for implicit evaluation of temperature $T$ by the Newton iteration method through the thermodynamic relationship $\rho e=\rho h-p$, i.e.

$$
\rho e-\frac{1}{2} \rho \mathbf{u}^{2}=\sum_{k=1}^{N} \rho_{k}\left(\int_{T_{0}}^{T} \frac{c_{p k}}{M_{k}} d T+h_{k}^{0}\right)-R T \sum_{k=1}^{N} \frac{\rho_{k}}{M_{k}}
$$

where $c_{p k}$ is the specific heat at constant pressure, and $h_{k}^{0}$ is the heat of formation at a reference temperature $T_{0}$. The specific heats are expressed as function of temperature in a polynomial fitting:

$$
\frac{c_{p k}}{R}=a_{1 k}+a_{2 k} T+a_{3 k} T^{2}+a_{4 k} T^{3}+a_{5 k} T^{4},
$$

where the coefficients $a_{i k}(i=1-5)$ are taken from CHEMKIN software based on the NASA thermochemical polynomial data [19], which are valid for temperature domain up to $6000 K$.

\section{Turbulence model}

The shear-stress transport (SST) turbulence model has a similar form as the Wilcox $k-\omega$ model. It combines the advantages of the Wilcox $k-\omega$ and the standard $k-\varepsilon$ model. The SST model gradually changes from the $k-\omega$ model in the inner region of the boundary layer to a highReynolds-number version of the $k-\varepsilon$ model in the outer region of the boundary layer and beyond. The model equations are

$$
\begin{array}{r}
\frac{\partial}{\partial t}(\rho k)+\frac{\partial}{\partial x_{i}}\left(\rho u_{i} k\right)=\frac{\partial}{\partial x_{i}}\left[\left(\mu+\frac{\mu_{t}}{\sigma_{k}}\right) \frac{\partial k}{\partial x_{i}}\right] \\
+P_{k}-\beta^{\prime} \rho k \omega, \\
\frac{\partial}{\partial t}(\rho \omega)+\frac{\partial}{\partial x_{i}}\left(\rho u_{i} \omega\right)=\frac{\partial}{\partial x_{i}}\left[\left(\mu+\frac{\mu_{t}}{\sigma_{\omega}}\right) \frac{\partial \omega}{\partial x_{i}}\right] \\
+\left(1-F_{1}\right) 2 \rho \frac{1}{\sigma_{\omega 2} \omega} \frac{\partial k}{\partial x_{i}} \frac{\partial w}{\partial x_{i}}+\alpha_{2} \frac{\omega}{k} P_{k}-\beta_{2} \rho \omega^{2},
\end{array}
$$

where the model constants are given by $\beta^{\prime}=0.09, \sigma_{k}=$ $1.176, \sigma_{\omega}=2, \alpha_{2}=0.44, \beta_{2}=0.0828, \sigma_{\omega 2}=1 / 0.856$.

The equation of $\omega$ is multiplied by blending function $1-F_{1}$ to ensure that the model equations behave appropriately in both the near-wall and far-field zones. The turbulent viscosity will be calculated by:

$$
\mu_{t}=\frac{a_{1} k \rho}{\max \left(a_{1} w, \Omega F_{2}\right)},
$$

where coefficient $a_{1}=0.31 . F_{2}$ is blending function similar to $F_{1}$, which restricts the limiter to the wall boundary layer. Here $\Omega$ is the strain rate tensor. 
The blending functions are critical to the success of the method. Their formulation is based on the distance to the nearest wall surface and the local flow quantities as:

$$
F_{1}=\tanh \left(\arg _{1}^{4}\right)
$$

with

$$
\arg _{1}=\min \left(\max \left(\frac{\sqrt{k}}{\beta^{\prime} \omega y}, \frac{500 \nu}{y^{2} \omega}\right), \frac{4 \rho k}{C D_{k \omega} \sigma_{\omega 2} y^{2}}\right),
$$

where $y$ is the distance to the nearest wall surface, $\nu$ is the kinematic viscosity. The cross-diffusion term is determined as:

$$
\begin{gathered}
C D_{k, \omega}=\max \left(2 \rho \frac{1}{\sigma_{\omega 2} \omega} \frac{\partial k}{\partial x_{i}} \frac{\partial \omega}{\partial x_{i}}, 1.0 \times 10^{-10}\right), \\
F_{2}=\tanh \left(\arg _{2}^{2}\right)
\end{gathered}
$$

with

$$
\arg _{2}=\max \left(\frac{2 \sqrt{k}}{\beta^{\prime} \omega y}, \frac{500 \nu}{y^{2} \omega}\right) .
$$

A disadvantage of standard two-equation turbulence models is the excessive evaluation of turbulent kinetic energy production, $P_{k}$, in the vicinity of stagnation points. In order to avoid the build-up of turbulent kinetic energy in stagnation regions, a formulation of limiter for the production term in the $k-\omega$ equations is introduced by Menter [14] as:

$$
\begin{gathered}
P_{k}=\mu_{t} \frac{\partial u_{i}}{\partial x_{j}}\left(\frac{\partial u_{i}}{\partial x_{j}}+\frac{\partial u_{j}}{\partial x_{i}}\right), \\
P_{k}=\left(P_{k}, 10 \rho \beta k \omega\right) .
\end{gathered}
$$

\section{Combustion model}

The chemical reaction source term in Eq.(9) will be calculated using the Eddy Dissipation combustion model (EDM). This model was developed by Magnussen and Hjertager in 1975. It is based on the same fundamental grounds as Spalding's model. For non-premixed flames, fuel and oxygen occur in separate eddies. Since chemical reactions occur very fast, the rate of combustion can be assumed to be determined by the rate of intermixing of the fuel and oxygen eddies at molecular scale, which is given by the rate of dissipation of the eddies. Since there is a correlation between the fluctuation in the concentration of fuel and oxygen and their respective mean values, the rate of reaction can be expressed by the mean concentration of the reacting species. Accordingly, for non-premixed flames, depending on whether the flame is locally fuel-starving or oxygen-starving, the rate of combustion of fuel can be expressed as:

$$
\dot{\omega}_{f u e l}=A \widetilde{C}_{f u e l} \frac{\varepsilon}{k}
$$

or

$$
\dot{\omega}_{f u e l}=A \frac{\widetilde{C}_{\text {ox }}}{(O / F)_{\text {stoic }}} \frac{\varepsilon}{k}
$$

where $\mathrm{A}$ is a constant which depends on the structure of the flame and the rate of reaction between the fuel and oxygen, $\widetilde{C}_{f u e l}$ is the local mean fuel concentration $\left(\mathrm{kg} / \mathrm{m}^{3}\right)$ , $\widetilde{C}_{o x}$ is the local mean oxygen concentration $\left(\mathrm{kg} / \mathrm{m}^{3}\right)$, and $(O / F)_{\text {stoic }}$ is the stoichiometric oxygen to fuel ratio. For premixed flames, fuel and oxygen occur in the same eddies. These eddies are separated by eddies containing hot combustion products. The rate of combustion can be assumed to be determined by the rate of separation of these hot eddies, which is given by the same mechanism as outlined above. However, an extra equation needs to be introduced that accounts for the dissipation of hot eddies in cases where the concentrations of hot combustion products is low. Hence, for premixed flames,

$$
\dot{\omega}_{\text {fuel }}=A B \frac{\widetilde{C}_{\text {prod }}}{1+(O / F)_{\text {stoic }}} \frac{\varepsilon}{k},
$$

where B is a constant, $\widetilde{C}_{\text {prod }}$ is the local mean concentration of the combustion products. These three equations (30), (31), and (32) are assumed to be generally applicable to both non-premixed and premixed turbulent flames. The equation that yields the minimum reaction rate is the one that determines the local rate of combustion. The main advantage of this model over Spalding's model is that it is applicable for both non-premixed and premixed flames. This makes it more suitable for combustion applications such as direct injection engines where combustion occurs in both premixed and non-premixed regimes. Also the importance is the fact that the combustion rate is proportional to the mean concentration of the intermittent quantities instead of the concentration fluctuations, which are difficult to estimate than the mean quantities.

The global reaction will be calculated from the minimum of the $\dot{\omega}_{E D M}$ and the minimum of $\dot{\omega}_{\text {Arrhenius }}$ :

$$
\dot{\omega}=\min \left(\dot{\omega}_{E D M}, \dot{\omega}_{\text {Arrhenius }}\right),
$$

where the Arrhenius reaction rate is expressed as:

$$
\dot{\omega}_{\text {Arrenhuis }}=A T^{\beta} e^{\left(-E_{a} / R T\right)}[\text { fuel }]^{a}[\text { oxygen }]^{b} .
$$

The constant $A$ is the pre-exponential factor in (cm3.mole.s1 ), $E_{a}$ the activation energy, the constant $a$ and $b$, are the degrees of reaction given by Jones and Lindstedt [20], and Westbrook and Dryer [21]. Equation (33) means that if the turbulence is weak, the reaction rate will be calculated from the Arrhenius law, and when the flow is fully turbulent the EDM will be utilized. The EDM relies on the idea that chemical reactions occur in the smallest turbulence eddies. It is the Damköhler number which classifies whether Arrhenius approach or the Eddy Dissipation Model will be utilized. If $D_{a}$ is small compared to unity, the chemical induction time is thus close to the limit and the Arrhenius law is used. If $D_{a}$ exceeds unity, the reaction rate is predominately influenced by flow turbulence and the Eddy Dissipation Model is selected. Bengherbia et al. [10-13] investigated the combustion process in the ram accelerator using different reaction mechanisms, including global one-step reaction, two-step, three-step, and 
five-step reaction mechanisms. Among the models tested, the results of the five-step reaction model are in better agreement with experimental data.

The aforementioned reaction rate is defined using the law of mass fraction and a modified Arrhenius expression for the specific heat constants $[21,22,23]$ as:

$$
\dot{\omega}_{\text {Arrhenius }}=A T^{\beta} e^{\left(-E_{a} / R T\right)} \sigma_{C H_{4}}^{a} \sigma_{\mathrm{O}_{2}}^{b} \sigma_{C O}^{c} \sigma_{H_{2}}^{d} \sigma_{C O_{2}}^{e} \sigma_{H_{2} O}^{f},
$$

where the $A T^{\beta}$ is the collision frequency, the exponent $\beta$ is the Boltzmann factor, the universal gas constant $R=$ $1.987 \mathrm{cal} / \mathrm{mole}-\mathrm{K}$, the $\sigma$ is the species mass fraction, and the coefficients $a, b, c, d, e, f$ are the degrees of reaction for each species. Note that the exponent $\beta=0$ is used for current five-step reaction mechanism as:

$$
\begin{gathered}
\mathrm{CH}_{4}+0.5 \mathrm{O}_{2} \rightarrow \mathrm{CO}+2 \mathrm{H}_{2} \\
\mathrm{H}_{2}+1 / 2 \mathrm{O}_{2} \rightarrow \mathrm{H}_{2} \mathrm{O} \\
\mathrm{CO}+0.5 \mathrm{O}_{2} \rightarrow \mathrm{CO}_{2} \\
\mathrm{CO}+\mathrm{H}_{2} \mathrm{O} \rightarrow \mathrm{CO}_{2}+\mathrm{H}_{2} \\
\mathrm{CO}_{2}+\mathrm{H}_{2} \rightarrow \mathrm{CO}+\mathrm{H}_{2} \mathrm{O}
\end{gathered}
$$

Table 1. Reaction rate equation data $(\beta=0)$

\begin{tabular}{lcccccccc}
\hline \hline Reaction & $E_{a}$ & $\mathrm{~A}$ & $\mathrm{a}$ & $\mathrm{b}$ & $\mathrm{c}$ & $\mathrm{d}$ & $\mathrm{e}$ & $\mathrm{f}$ \\
\hline Eq.(35) & 30 & $2.3 \times 10^{7}$ & -0.3 & 1.3 & 1 & 1 & 0 & 0 \\
Eq.(36) & 37.6 & $1 \times 10^{5}$ & 0 & 0.5 & 0 & 1 & 0 & 1 \\
Eq.(37) & 40 & $3.5 \times 10^{14}$ & 0 & 0.25 & 1 & 0 & 1 & 0 \\
\hline
\end{tabular}

The forward reaction for the Eq. (41) will be calculated by

$$
\dot{\omega}_{F}=\frac{X_{C O}}{W_{C O}} \times X_{H 2 O} \times P_{a b s}^{2} \times 8.110^{-9} \times e^{-10926.5 / T},
$$

The backward reaction for the Eq. (42) will be calculated by

$$
\dot{\omega}_{B}=\frac{X_{C O 2}}{W_{C O}} \times X_{H 2} \times P_{a b s}^{2} \times 3.310^{-7} \times e^{-15144 / T} .
$$

where $X_{i}$ is the mole fraction, $W_{i}$ is the molecular weight and $P_{a b s}$ is absolute pressure. The equations (41) and (42) have been developed by Kovacik [24] and validated against wide range of experimental data.

\section{Radiation model}

In the present formulation of the P-1 model [25], four terms in the series expansion are used and the following equation is obtained for the radiation flux $q_{r}$.

$$
q_{r}=-\frac{1}{3\left(\alpha+\sigma_{s}\right)-C \sigma_{s}} \nabla G
$$

where $\alpha$ is the absorption coefficient, $\sigma_{s}$ is the scattering coefficient, $G$ is the incident radiation and $C$ is the linear anisotropic phase function coefficient. It ranges from -1 to +1 and represents the amount of radiation scattered in forward or backward direction. A positive value indicates that more radiant energy is scattered forward than backward with $C=1$ standing for complete forward scattering. A zero value of $C$ defines isotropic scattering. This approximation is implemented in the present simulations.

The transport equation for $G$ is shown as:

$$
\nabla\left(\frac{1}{3\left(\alpha+\sigma_{s}\right)-C \sigma_{s}} \nabla G\right)-\alpha G+4 \alpha \sigma T^{4}=0
$$

where $\sigma$ is the Stefan-Boltzmann constant. Combining Eq. (43) and Eq. (44), we obtain:

$$
-\nabla q_{r}=\alpha G+4 \alpha \sigma T^{4}
$$

where the expression for radiation flux gradients can be directly substituted into the energy equation to account for heat sources or sinks due to radiation. The flux of the radiation at walls, $q_{r, w}$, caused by incident radiation $G_{w}$ is given from Eq.(46) and $e_{w}$ is wall emissivity.

$$
q_{r, w}=-\frac{e_{w}}{2\left(2-e_{w}\right)}\left(4 \sigma T_{w}^{4}-G_{w}\right) .
$$

\section{Flame radiation losses}

The determination of the Planck-mean absorption coefficient takes into account the effect of the gas band radiation. For gas band radiation, $\mathrm{CO}_{2}$ and $\mathrm{H}_{2} \mathrm{O}$ are the most important radiating species in hydrocarbon flames. $\mathrm{CO}$ and $\mathrm{CH}_{4}$ contribute much less to the flame temperature reduction than do $\mathrm{CO}_{2}$ and $\mathrm{H}_{2} \mathrm{O}$. However, it was suggested to consider all four species in a radiation [26]. The Planck coefficients for methane $\left(\mathrm{CH}_{4}\right)$, water $\left(\mathrm{H}_{2} \mathrm{O}\right)$, carbon monoxide $(\mathrm{CO})$ and carbon dioxide $\left(\mathrm{CO}_{2}\right)$ were taken from the RADCAL program of Grosshandler [27] (Figure 2).

\section{Computational procedure}

The numerical simulation code used for this research effort is the ANSYS-CFX CFD code [28]. It is a finitevolume code that solves a system of coupled nonlinear partial differential equations (PDE's) for a compressible multi-component turbulent flow, corresponding to conservation of mass (continuity), momentum, absolute enthalpy and species mass fractions. ANSYS-CFX employs an iterative time-implicit pressure-based sequential procedure for the solution of the governing equations. Favre-averaged dependent variables are calculated and a standard two equation SST model is used for turbulent closure. The conservation equations discretised and solved on a structured mesh, the discretization accuracy is first-order in 


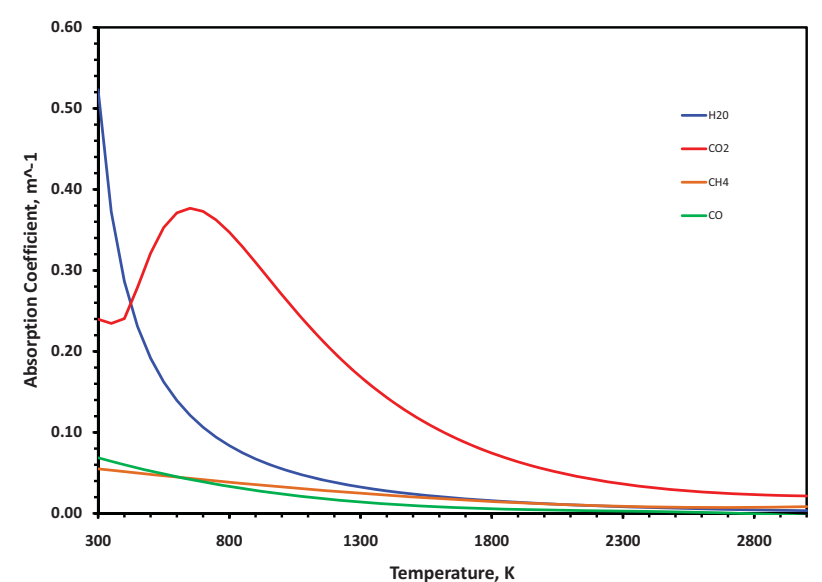

Fig. 2. Planck mean absorption coefficient for $\mathrm{CO}_{2}, \mathrm{H}_{2} \mathrm{O}, \mathrm{CH}_{4}$ and $C O$ as function of gas temperature [27]

time and second-order in space. Second order Total Variation Diminishing (TVD) scheme is used for capturing the shock waves $[29,30]$

ANSYS-CFX is also suitable for chemically reacting flows, with ports for incorporation of additional sub-models. In this research, we incorporate detail chemistry in user-defined sub-routines.

\subsection{Geometry}

The projectile body has a bi-conical shape with the nose cone having a half-angle of 10 and a length of $82 \mathrm{~mm}$, whereas the aftbody is represented by a truncated cone having a convergence angle of 4.493 and a length of 71 $\mathrm{mm}$, as shown in Figure 3. The projectile throat has a maximum diameter of $29 \mathrm{~mm}$, situated at the joint of the two cones. The overall length of the projectile is $153 \mathrm{~mm}$.

In the present study two dimensional geometry will be considered in the computational domain, the projectile is located at $10 \mathrm{~mm}$ from the inlet plane. The computational domain length is $500 \mathrm{~mm}$ (i.e., approximately three times of the projectile length, $L_{p}$ ).

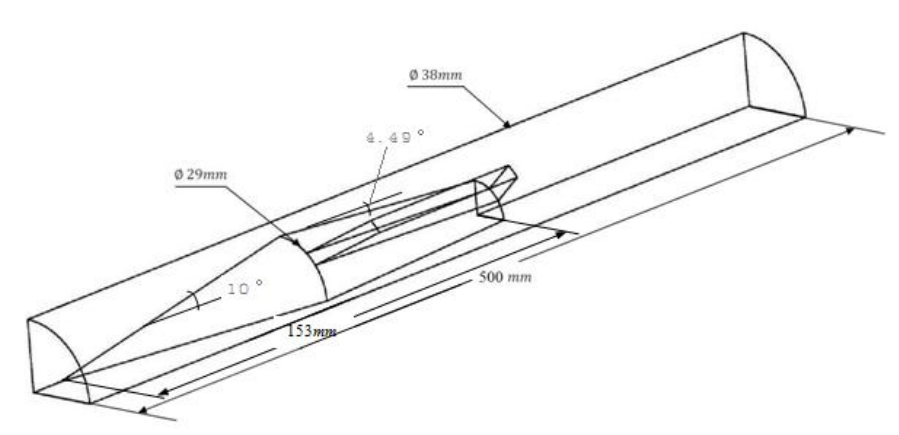

Fig. 3. The ram accelerator geometry model

\subsection{Mesh guidelines}

To determine the required near wall mesh spacing, a target value of $\Delta y_{w}^{+}$, based on the wall unit can be generated. Here we adopted an hybrid method developed by Menter [10] for the SST turbulence model, in which the near-wall treatments will automatically switch from a low-Re formulation to wall functions based on the grid spacing. The SST model has the advantages than an analytical expression for $\omega$ in the viscous sublayer. The main idea behind the present formulation is to blend the wall value for $\omega$ between the logarithmic region and the near wall formulations. The flux for the k-equation is artificially kept to be zero and the flux in the momentum equation is computed from the velocity profile. The equations are as follows:

Flux for the momentum equation, $F_{U}$ :

$$
F_{u}=-\rho u_{\tau} u^{*}
$$

with

$$
u_{\tau}=\sqrt{\nu\left|\frac{\Delta U}{\Delta y}\right|_{w}}
$$

and

$$
u^{*}=\max \left(\sqrt{a_{1} k}, u_{\tau}\right),
$$

where $U$ is the mean velocity, $u_{\tau}$ is friction velocity.

Flux for the k-equation:

$$
F_{k}=0
$$

In the $\omega$-equation, an algebraic expression is specified instead of an additional flux. It is blended between the analytical expression for $\omega$ in the logarithmic region:

$$
\omega_{l}=\frac{u^{*}}{a_{1} \kappa y}=\frac{1}{a_{1} \kappa \nu} \frac{u^{* 2}}{y^{+}},
$$

where $\kappa$ is the von Karman constant. The corresponding expression in the sublayer:

$$
\omega_{s}=\frac{6 \nu}{\beta(\Delta y)^{2}},
$$

with $\Delta y$ being the mesh size in the wall-normal direction. In order to achieve a smooth blending and avoid cyclic convergence behavior, the following formulation is selected:

$$
\omega_{\omega}=\omega_{s} \sqrt{1+\left(\frac{\omega_{l}}{\omega_{s}}\right)^{2}}
$$

This formulation provides the optimal boundary condition for a given grid. This method is the most desirable, as it allows for an accurate near-wall treatment over a wide range of grid spacings. It requires a minimum of at least 10 grid nodes inside the boundary layer thickness, for flows with high-Re number, e.g. at an order of $10^{8}$, the value of $y^{+}$in the near wall region can exceed 1000 . 
The wall-function described above requires a minimum value of $\Delta y^{+}<200$. The estimation can be made based on the following correlations:

$$
\Delta y=L \Delta y^{+} \sqrt{80} R e_{L}^{-0.9285},
$$

where $L$ is the computational domain length, $\Delta y$ is the near wall mesh size, $\Delta y^{+}$is the target wall unit value. For example, by setting the target to 1 for incoming velocity $V_{\infty}=1091 \mathrm{~m} / \mathrm{s}$, it require a near wall mesh space of $0.14 \mu \mathrm{m}$ and it is about $0.095 \mu \mathrm{m}$ for incoming velocity $V_{\infty}=2027 \mathrm{~m} / \mathrm{s}$

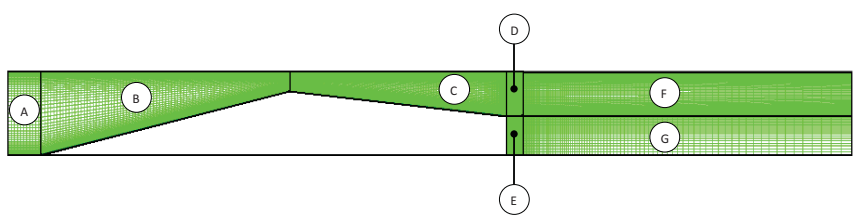

Fig. 4. Block structured mesh topology around the projectile

A series of structured meshes have been generated which have the same topology as shown in figure 4, with nearwall size given in table 2 . The total number of elements per block are given in table 3 .

Table 2. Mesh size in the near-wall region

\begin{tabular}{lcccccc}
\hline \hline $\begin{array}{l}\text { Mesh } \\
\Delta y\end{array}$ & $\begin{array}{c}\mathrm{A} \\
(\mu m)\end{array}$ & $\begin{array}{c}\mathrm{B} \\
(\mu \mathrm{m})\end{array}$ & $\begin{array}{c}\mathrm{C} \\
(\mu \mathrm{m})\end{array}$ & $\begin{array}{c}\mathrm{D} \\
(\mu \mathrm{m})\end{array}$ & $\begin{array}{c}\mathrm{E} \\
(\mu \mathrm{m})\end{array}$ & $\begin{array}{c}\mathrm{F} \\
(\mu \mathrm{m})\end{array}$ \\
\hline 1 & 0.14 & 0.1 & 0.1 & 0.3 & 0.1 & 0.4 \\
2 & 0.095 & 0.09 & 0.095 & 0.095 & 0.1 & 0.54 \\
3 & 19 & 5 & 10 & 10 & 6 & 10 \\
4 & 28 & 6.6 & 15 & 15 & 6 & 15 \\
\hline
\end{tabular}

Table 3. Approximate total number of mesh elements

\begin{tabular}{lccccccc}
\hline \hline Mesh & A & B & C & D & E & F & G \\
\hline 1 & 10000 & 100000 & 200000 & 10000 & 10000 & 50000 & 50000 \\
2 & 20000 & 200000 & 400000 & 40000 & 30000 & 200000 & 100000 \\
3 & 5600 & 33600 & 67200 & 11200 & 5000 & 56000 & 25000 \\
4 & 5000 & 30000 & 60000 & 10000 & 5000 & 50000 & 25000 \\
\hline
\end{tabular}

Precursor simulations [10] were carried out to determine a suitable mesh for the present study. From simulations using four meshes presented in table 2, it was found that results from mesh 4 give good convergence. Thus this mesh will be used for all the rest simulations.

\subsection{Determining turbulence parameters}

Two parameters must be determined for flow at the inlet plane, i.e. the turbulence intensity $I$, and the turbulence length scale $\ell$. The turbulence intensity can be estimated from the following formula derived from an empirical correlation for pipe flows:

$$
I \equiv \frac{u^{\prime}}{u_{a v g}}=0.16(R e)^{-1 / 8},
$$

where $u^{\prime}$ is the velocity fluctuations, $u_{a v g}$ is the mean flow velocity.

The turbulence length scale $\ell$, is a physical quantity related to the size of the large eddies that contain the energy in turbulent flows. An approximation can be made using the following formula:

$$
\ell=C_{\mu} \frac{k^{3 / 2}}{\varepsilon}
$$

This correlation is suitable approximation has been used in present simulation. The smallest length scale in the domain is the Kolmogorov scales $\eta$ given by:

$$
\eta=\left(\frac{\nu^{3}}{\varepsilon}\right)^{1 / 4} .
$$

The turbulence length scale are between the Kolmogorov scale and the integral length scale as $\eta \ll \ell \ll \ell_{t}$. The integral length scale can calculated from the following formula:

$$
\ell_{t}=\eta R e_{t}^{3 / 4},
$$

where the turbulence Reynolds number $R e_{t}=u^{\prime} l / \nu$. For very high Reynolds number flow, the viscous effects are restricted to very thin boundary layer.

\subsection{Boundary conditions}

\subsubsection{Supersonic inflow condition}

For supersonic inflow, there are no outgoing characteristic waves from the computational domain up to the boundary points. All flow quantities at the inlet boundary therefore need to be prescribed. Figure 5 gives the turbulence intensity variations with incoming flow speed, where the turbulence length scale is kept to be $10^{-5} \mathrm{~m}$ based on estimated $\eta$ and $\ell_{t}$ values.

\subsubsection{Supersonic outflow condition}

For supersonic outflow, all characteristics from an inner boundary point will leave the computational domain. Therefore, a linear extrapolation can be made from the interior cells to the boundary points. 


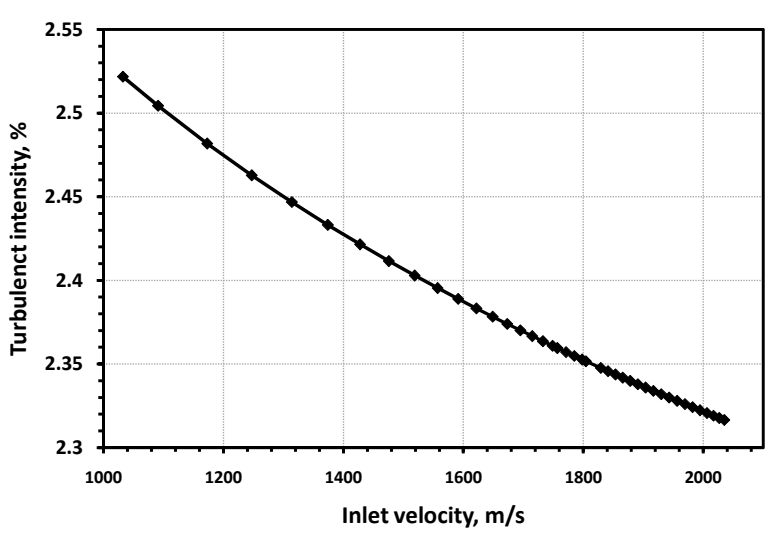

Fig. 5. Turbulent intensity vs incoming velocity at inlet plane

\subsubsection{Wall boundary condition}

The flow around the ram accelerator is considered as viscous flow, thus a no-slip boundary condition is applied on all the walls, with the tube wall moving at the same speed of incoming flow velocity. In addition, the tube wall is treated as isothermal wall, i.e. $T_{\text {wall }}=300 \mathrm{~K}$, and the projectile walls as adiabatic and non-catalytic. Taking into account the radiation effects, all walls are also treated as a grey heat sink with the emissivity factor 1 , while the wall scattering coefficient is taken to be zero.

\section{Results and discussions}

Non reactive flow simulations were performed at first for a range of incoming flow velocities as seen in Figure 5. The results are then used as initial flow field to run the reactive flow simulation of the ram accelerator.

The axial thrust from computations using five-step reaction model is determined by integrating the pressure distributions over the surface of the projectile. Figure 6 shows that the thrusts at all incoming Mach numbers up to $M_{\infty}=4.4\left(V_{\infty}=1622 \mathrm{~m} / \mathrm{s}\right)$ are 8 to $21 \%$ greater than experimental measurements, however the predicted thrusts between $M_{\infty}=4.4$ and $M_{\infty}=5.1$ are in good agreement with experimental data. The discrepancy in thrust is probably partly due to lack of fin drag being considered in the calculations. Another factor not considered in the CFD modeling is the unsteadiness of the flow field, i.e., the projectile acceleration under these conditions was $\sim 25,000$ gee. The experimental thrust seen in figure 6 deviates significantly from the theoretical calculation at $V_{\infty} \approx 1800 \mathrm{~m} / \mathrm{s}$. This is due to the projectile making a transition from the thermally choked propulsive mode to the transdetonative mode in which the combustion moves up on the projectile body and the flow ceases to be thermally choked behind it [3]. This transition occurs when the projectile reaches approximately $90 \%$ of the Chapman-Jouguet speed. The current calculation attempts to predict the ram accelerator performance while it is operating in the thermally choked propulsive mode.

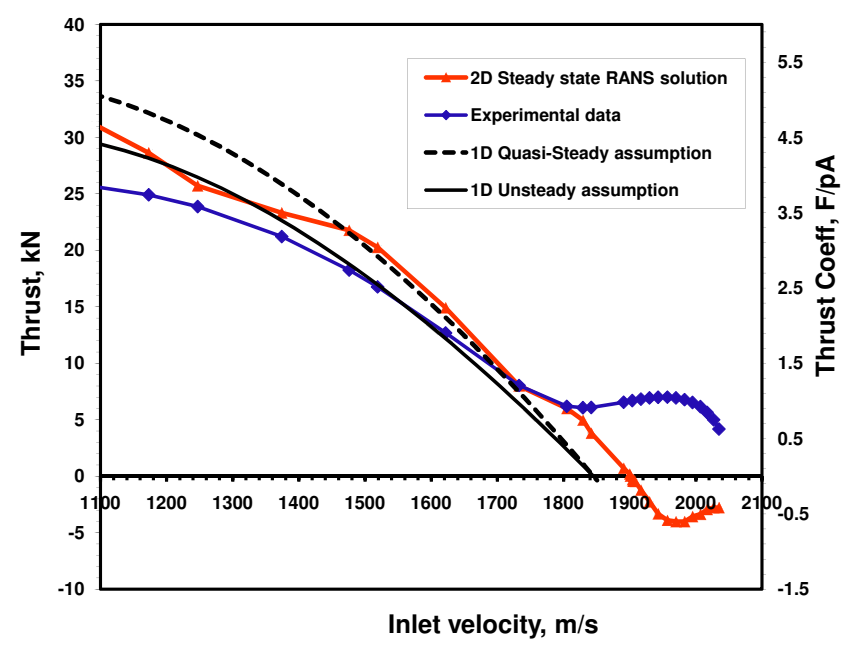

Fig. 6. Comparison of the CFD predicted thrust with experimental data.

Figure 6 also compares the CFD thrust with that from one-dimensional modeling, both quasi-steady and unsteady assumptions are considered for comparison. These calculations have been obtained by using a one-dimensional computer program called TARAM [31], results show that accounting for projectile acceleration reduces predicted thrust in amounts consistent with experiments [9].

The results show that the CFD determined thrusts are in good agreement with unsteady one-dimensional prediction at lower Mach number between $M_{\infty}=2.92$, and $M_{\infty}=3.9$; however between $M_{\infty}=4.4$ and $M_{\infty}=4.8$, the CFD thrusts are in perfect match with that predicted by quasi-steady one-dimensional modeling. Increases in CFD determined thrusts were observed after $M_{\infty}=4.9$ by 10 to $14 \%$. The thrust equal zero represents the thrust for which the speed is the Chapman-Jouguet (C-J) detonation speed in the one-dimensional model. The detonation speed predicted by one-dimensional modeling for the present propellant is about $1845 \mathrm{~m} / \mathrm{s}$, whereas CFD predicts thrust to equal zero at $1901 \mathrm{~m} / \mathrm{s}$, which is in reasonably good agreement.

Table 4 shows the position and the experiment recorded projectile velocity at these points. The recorded pressure at these locations presents the successful operation of the thermally choked propulsion mode, where the high pressure is located at the base of the projectile. For the pressure comparison, the reference $x=0$, was taken at the noise tip of the projectile.

Figure 7 and figure 8 present the pressure profiles on the tube wall for the in-coming velocities $V_{\infty}$ of: 1091 , $1120,1150,1173,1200$, and $1247 \mathrm{~m} / \mathrm{s}$ respectively. The 
Table 4. Pressure tracers position

\begin{tabular}{lcc}
\hline \hline Station & $\mathrm{X}(\mathrm{mm})$ & $\mathrm{V}(\mathrm{m} / \mathrm{s})$ \\
\hline P3 & 1000 & 1240 \\
P5 & 1800 & 1380 \\
P6 & 2198 & 1430 \\
P8 & 2998 & 1520 \\
P10 & 3798 & 1590 \\
P15 & 5796 & 1720 \\
P16 & 6194 & 1740 \\
P18 & 6994 & 1760 \\
P25 & 9792 & 1850 \\
P38 & 14986 & 2020 \\
\hline
\end{tabular}

predicted pressure peaks are at similar locations in comparison to data measured at $\mathrm{P} 3$ with projectile velocity of $V=1240 \mathrm{~m} / \mathrm{s}$. Good comparison was also observed in the far field behind the projectile base. It was found that the normal shock position on the projectile after-body changes position as a function of the incoming velocity; i.e, $x \approx 0.16 \mathrm{~m}$ at in-coming velocity of $V_{\infty}=1091 \mathrm{~m} / \mathrm{s}$ to $x \approx 0.15 \mathrm{~m}$ at $V_{\infty}=1150 \mathrm{~m} / \mathrm{s}$, then receding back to about $x=0.16 \mathrm{~m}$ at $V_{\infty}=1200 \mathrm{~m} / \mathrm{s}$. These positions can be more accurately determined when including the guiding fins in the modeling. Some previous works $[18,19]$ attempted to predict the performance of the ram accelerator in the sub-detonative propulsion mode. Their results showed that the position of the normal shock will be affected by the presence of the guiding fins. Figure 9 shows the pressure profiles on the tube wall for in-coming velocity $V_{\infty}$ of: 1374 , and $1400 \mathrm{~m} / \mathrm{s}$ respectively. The trend of pressure variation and magnitude is similar between computation and experimental data at P5. The small fluctuation observed in the experiments between $x=0.1 \mathrm{~m}$ and $x=0.16 \mathrm{~m}$ does not appear in our modeling. This maybe due to the three-dimensional unsteady nature of the flow around the projectile, which is not considered in this modeling. At in-coming velocity $V_{\infty}$ of $1476 \mathrm{~m} / \mathrm{s}$ The pressure magnitude in the far field behind the projectile base $(x=0.153 \mathrm{~m})$ agreed well with measurements for the recorded data at $\mathrm{P} 6, \mathrm{P} 8$. The location and position of the normal shock are in better agreement with $\mathrm{P} 6$, as seen in figure 10. The simulation accurately predicts the magnitude of the peak pressures behind the projectile base $(x=0.19 \mathrm{~m})$. Overall, the pressure from the CFD prediction in the far field have the same magnitude compared to $\mathrm{P} 8$.

At in-coming velocity of $V_{\infty}$ of: $1520 \mathrm{~m} / \mathrm{s}$, the best comparison with experimental data is $\mathrm{P} 11$, where the positions of the pressures peaks are similar, and the decay in the magnitude behind the projectile is similar as in the experiment (figure 11).

Figures 12, 13 and 14 present the pressure profiles on the tube wall for in-coming velocity $V_{\infty}$ of: $1733,1820,2017$, and $2035 \mathrm{~m} / \mathrm{s}$. The pressure from the simulations were compared to the experimental data recorded at projectile having velocities $V_{\text {infty }}=1720,1740,1760,1850$ and
$2020 \mathrm{~m} / \mathrm{s}$. In general, the CFD modeling did not predict the pressure in the trans-detonative propulsion regime. This is mainly due to the fact that our modeling did not consider the $3 \mathrm{D}$ unsteady nature of the flow in the ram accelerator, where the shocks interaction resulting from the fins are neglected here.

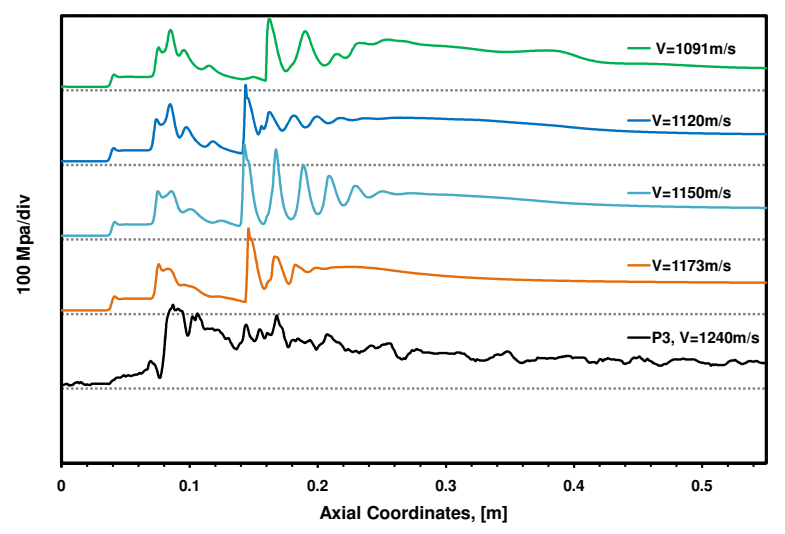

Fig. 7. Pressure profiles on the tube wall, Experimental velocity $\mathrm{P} 3=1240 \mathrm{~m} / \mathrm{s}$

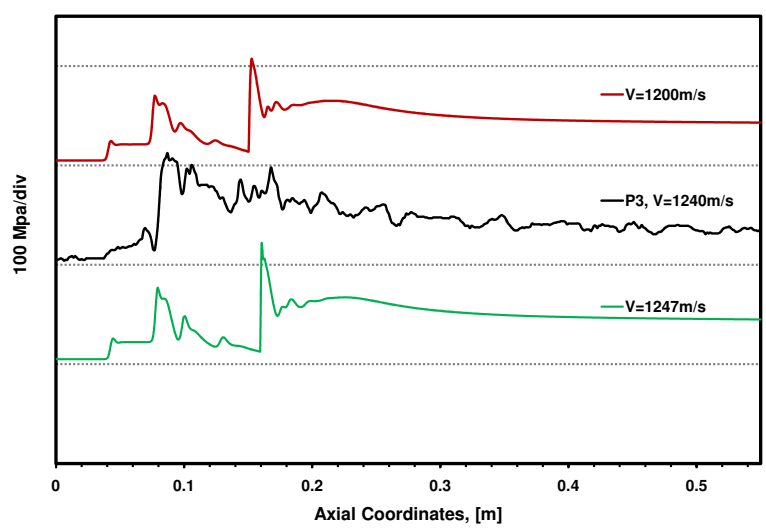

Fig. 8. Pressure profiles on the tube wall, Experimental velocity $\mathrm{P} 3=1240 \mathrm{~m} / \mathrm{s}$

Figure 15 present the methane oxidation contour for incoming velocity $V_{\infty}=1091,1173$ and $1829 \mathrm{~m} / \mathrm{s}$, respectively. It can be seen that at $V_{\infty}=1091 \mathrm{~m} / \mathrm{s}$, the reaction zone is about twice the projectile length. While incoming flow velocities increases, the reaction zone length decreases. A maximum thrust of $31 K N$ was obtained at $V_{\infty}=1091 \mathrm{~m} / \mathrm{s}$ (figure 6).

The temperature contours are shown in figure 16 which is consistent with the reaction zone. Of all simulations, the maximum flame temperature of $T_{f}=1991 \mathrm{~K}$ is observed at $V_{\infty}=1091 \mathrm{~m} / \mathrm{s}$, and at $V_{\infty}=1829 \mathrm{~m} / \mathrm{s}$ we observe a very short length of reaction zone and the temperature seems to be close to the projectile base. Low temperature can be seen in the near tube wall region. 


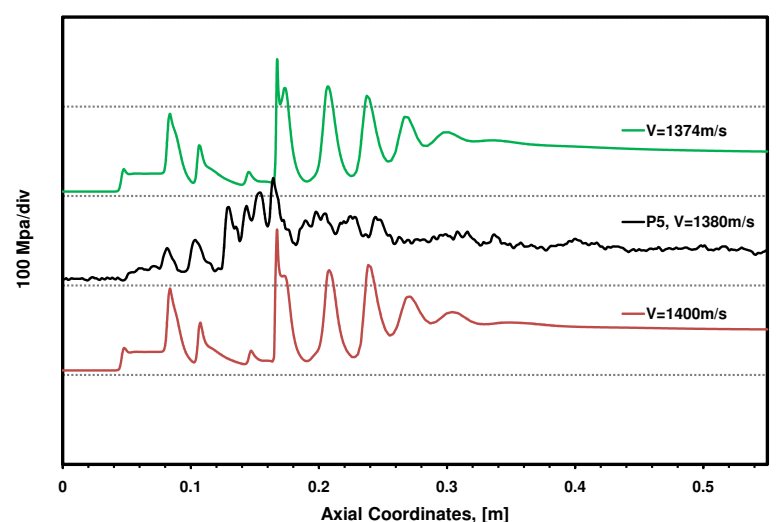

Fig. 9. Pressure profiles on the tube wall, Experimental velocity $\mathrm{P} 5=1380 \mathrm{~m} / \mathrm{s}$

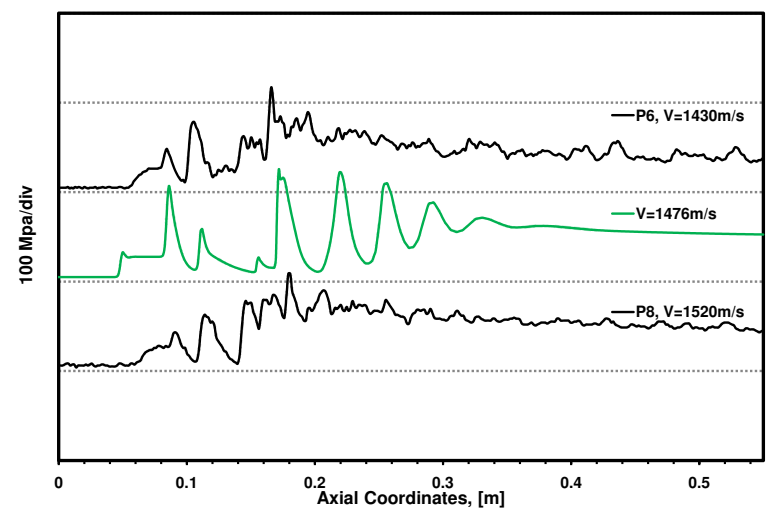

Fig. 10. Pressure profiles on the tube wall, Experimental velocity; $\mathrm{P} 6=1430 \mathrm{~m} / \mathrm{s}, \mathrm{P} 8=1520 \mathrm{~m} / \mathrm{s}$

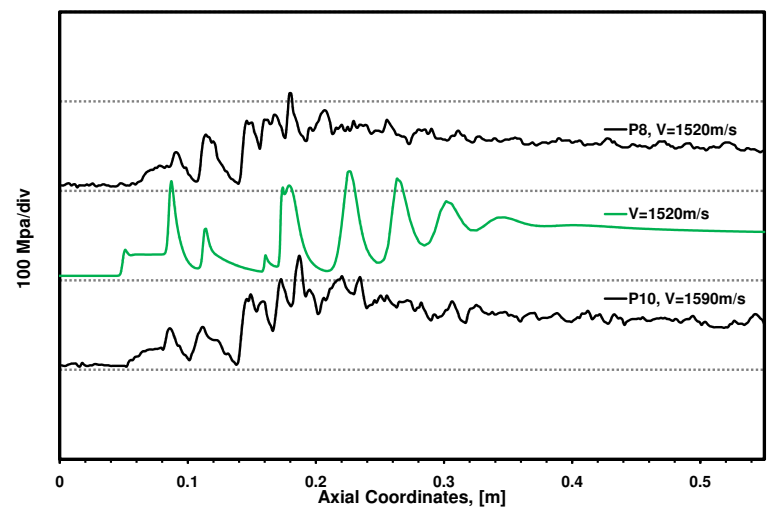

Fig. 11. Pressure profiles on the tube wall, Experimental velocity; $\mathrm{P} 8=1520 \mathrm{~m} / \mathrm{s}, \mathrm{P} 10=1590 \mathrm{~m} / \mathrm{s}$

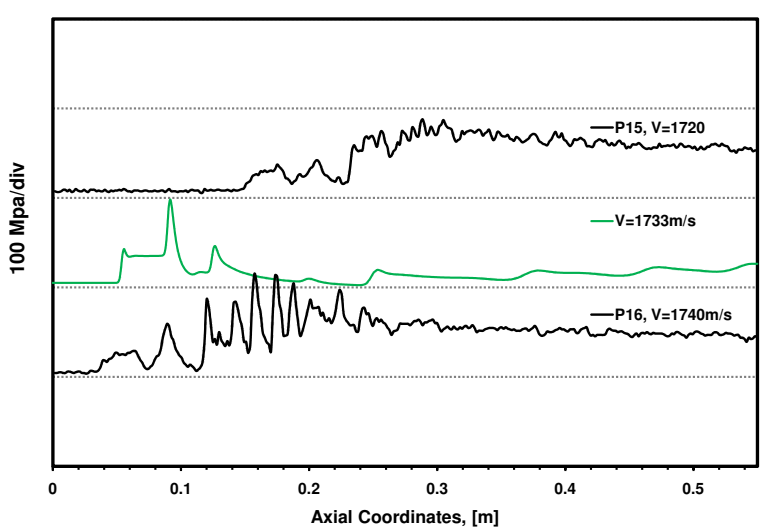

Fig. 12. Pressure profiles on the tube wall, Experimental velocity; $\mathrm{P} 15=1720 \mathrm{~m} / \mathrm{s}, \mathrm{P} 16=1740 \mathrm{~m} / \mathrm{s}$

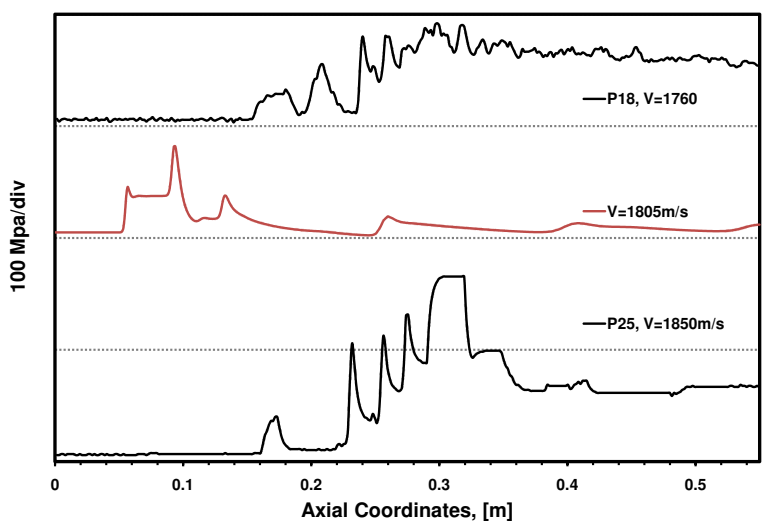

Fig. 13. Pressure profiles on the tube wall, Experimental velocity; $\mathrm{P} 18=1760 \mathrm{~m} / \mathrm{s}, \mathrm{P} 25=1850 \mathrm{~m} / \mathrm{s}$

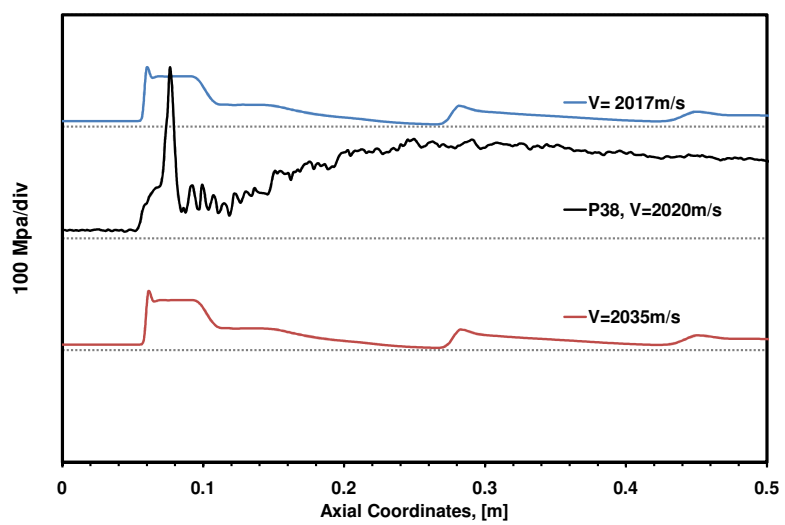

Fig. 14. Pressure profiles on the tube wall, Experimental velocity; P38=2020 m/s 
Figure 17 presents the pressure contours for incoming velocities of 1091,1173, and $1829 \mathrm{~m} / \mathrm{s}$, A high pressure was observed at the base of the projectile for velocity of $1091 \mathrm{~m} / \mathrm{s}$ with enhanced oscillations. It can be seen that an oblique shock wave formed at the rear of the projectile, which ends as a normal shock wave at the tube wall. While the inflow velocities increases, i.e $V_{\infty}=1173 \mathrm{~m} / \mathrm{s}$ the normal shock becomes an oblique shock with decreasing angle. At $V_{\infty}=1829 \mathrm{~m} / \mathrm{s}$, the oblique shock becomes less visible as the reflection shock from the tube wall is almost impinging on to the projectile trailing-edge location.

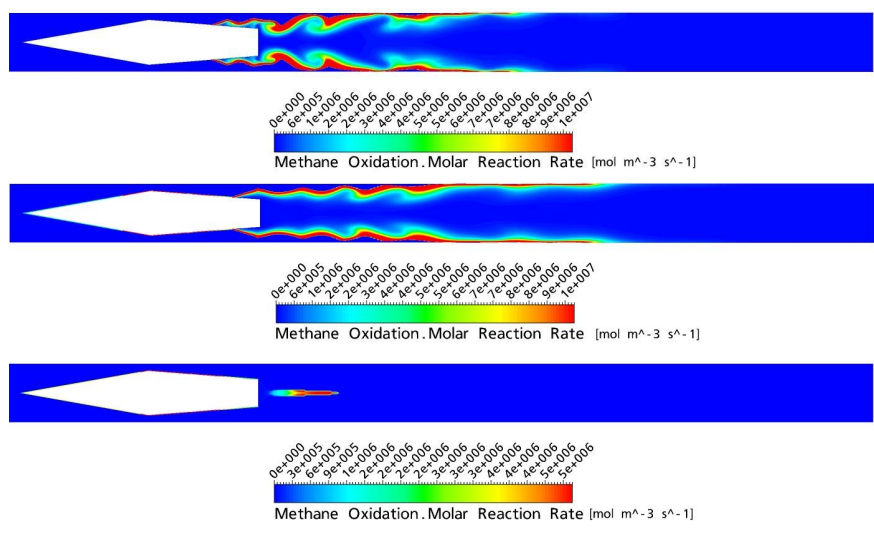

Fig. 15. Methane oxidation contours, incoming velocity $V_{\infty}=1091 \mathrm{~m} / \mathrm{s} ; I=2.5 \%$ (top), $V_{\infty}=1173 \mathrm{~m} / \mathrm{s} ; I=$ $2.48 \%$ (middle) and $V_{\infty}=1829 \mathrm{~m} / \mathrm{s} ; I=2.34 \%$ (bottom) respectively

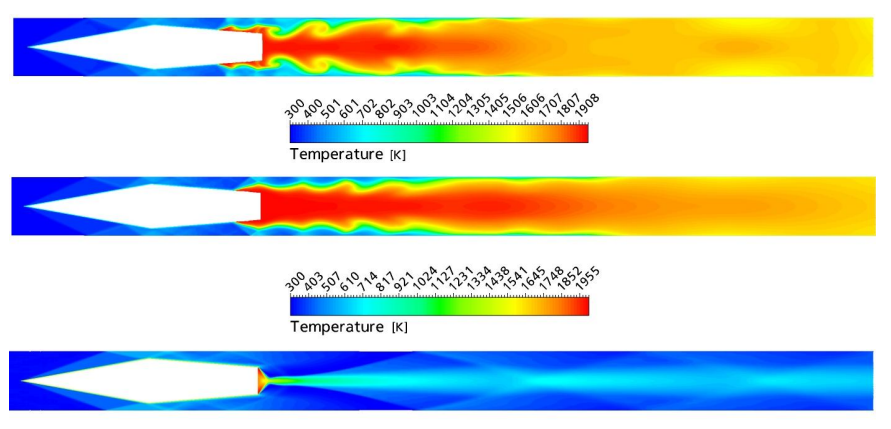

$$
\text { Temperature [K] }
$$

Fig. 16. Temperature contours, incoming velocity $V_{\infty}=1091 \mathrm{~m} / \mathrm{s} ; I=2.5 \%$ (top), $V_{\infty}=1173 \mathrm{~m} / \mathrm{s}$ $I=2.48 \%$ (middle) and $V_{\infty}=1829 \mathrm{~m} / \mathrm{s} ; I=2.34 \%$ (bottom) respectively
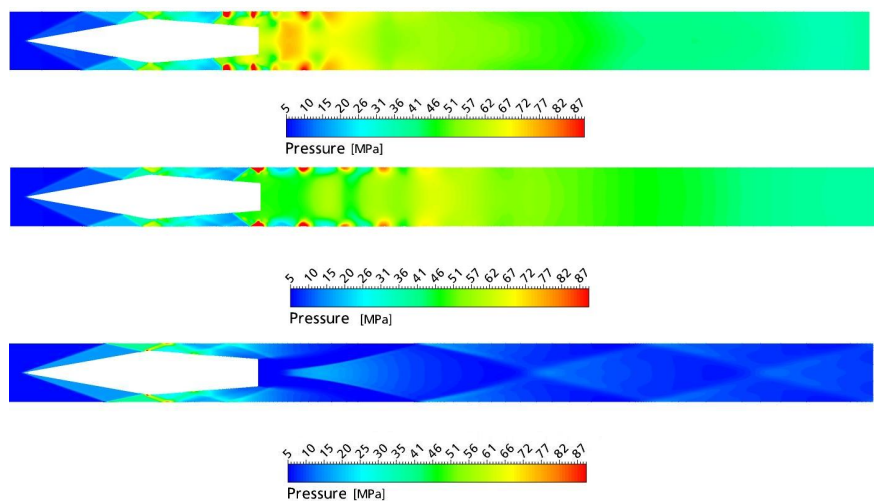

Fig. 17. Pressure contours, incoming velocity $V_{\infty}=$ $1091 \mathrm{~m} / \mathrm{s} ; I=2.5 \%$ (top), $V_{\infty}=1173 \mathrm{~m} / \mathrm{s} ; I=$ $2.48 \%$ (middle) and $V_{\infty}=1829 \mathrm{~m} / \mathrm{s} ; I=2.34 \%$ (bottom) respectively

\section{Conclusion}

A computational fluid dynamics study has been carried out to predict the thrust in the thermally choked ram accelerator propulsion mode. A series of different incoming velocities were adopted ranging from $V_{\infty}=1091 \mathrm{~m} / \mathrm{s}$ to $V_{\infty}=2035 \mathrm{~m} / \mathrm{s}$. The turbulent combustion flow has been modeled with the shear-stress transport model for the turbulence and the eddy dissipation model for combustion with reduced mechanism of five-step reaction. The simulations have reproduced combustion processes which are ignited automatically with high local temperature associated with the shock wave boundary layer interactions. The predicted thrust agrees reasonably well with both the experimental measurements and that derived from one-dimensional modeling at projectile velocities up to about $1800 \mathrm{~m} / \mathrm{s}$. The CFD predicted pressure variation and magnitude at several key measurement locations are in good agreements with the test record data. The present study also provides flowfield data regarding thermally choked ram accelerator thrust equal zero drag condition at near the C-J detonation speed. The flow features and the shock wave system around the projectile, which is important in determining the characteristics of the thermally choked propulsive mode, were investigated in the present study. These findings are useful in understanding the characteristics of supersonic turbulent combustion processes in the ram accelerator.

\section{References}

1. Hertzberg A, Bruckner, A.P., and Bogdanoff, D.W., "Ram Accelerator: A New Chemical Method for Accelerating Projectiles to Ultrahigh Velocities," AIAA Journal, Vol. 26, No. 2, 1988, pp. 195-203.

2. Bruckner, A.P., Knowlen, C., Hertzberg, A., and Bogdanoff, D.W., "Operational Characteristics of the Thermally Choked Ram Accelerator," Journal of Propulsion and Power, Vol. 7, No. 5, 1991, pp. 828-836. 
3. Hertzberg, A., Bruckner, A. P., and Knowlen, C., "Experimental Investigation of Ram Accelerator Propulsion Modes," Shock Waves, Vol. 1, No. 1, 1991, pp. 17-25.

4. Kruczynski, D. L., Liberatore, F., and Nusca, M. J., "Experimental Flow Visualization for a Large-Scale Ram Accelerator," Journal of Propulsion and Power, Vol. 12, No. 1, 1996, pp. 206-210.

5. Giraud M.J., Legendre, J.F., and Henner, M., "RAMAC in Subdetonative Propulsion Mode: State of the ISL Studies", Ram Accelerators, Takayama K., Sasoh A. (eds), SpringerVerlag, Heidelberg, 1998, pp. 65-78.

6. Li, C., "The Starting Process in Thermally Choked Ram Accelerator," AIAA 1999-969, January 1999.

7. Li, C., "Starting Performance in Thermally Choked Ram Accelerator at High Mixture Pressures," AIAA 1999-2950, Los Angeles, CA, June 1999.

8. Sasoh, A., Hamate, Y., and Takayama, K., "Small-Bore Ram Accelerator Operation," Journal of Propulsion and Power, Vol.17, 2001, pp.622-628.

9. Bauer, P., Knowlen, C., and Bruckner, A.P., "OneDimensional Modeling of Ram Accelerator at High Acceleration Rates in Sub-Detonative Velocity Regime," Eur. Phys. J. Appl. Phys. 29(3), 2005, pp. 253-258.

10. Bengherbia, T., Yao, Y., and Bauer, P., "Computational Investigation of Transitional Viscous Flow over a Ram Accelerator Projectile in Sub-Detonative Propulsion Mode," AIAA 2006-0558, January 2006.

11. Bengherbia, T., Yao Y., Bauer, P., Knowlen, C., and Bruckner, A.P., "Numerical Analysis of the Thermally Choked Ram Accelerator in Sub-detonative Regime," The 21th ICDERS, ENSMA - Poitiers, France, July 2007.

12. Bengherbia, T., Yao Y., Bauer, P., and Knowlen, C.,"Numerical Investigation of Thermally Choked Ram Accelerator in Sub-Detonative Regime," AIAA 20090635,January 2009.

13. Bengherbia, T., Yao Y., Bauer, P.,and Knowlen, C.,"Thrust Prediction in Thermally Choked Ram Accelerator," AIAA 2010-1129, January 2010.

14. Menter, F.R., "Zonal two Equation k- $\omega$ Turbulence Models for Aerodynamic Flows," AIAA 93-2906, 1993.

15. Magnussen, B.F., "On the Structure of Turbulence and a Generalized Eddy Dissipation Concept for Chemical Reactions in Turbulent Flow," AIAA 1981-42, 1981.

16. Magnussen, B.F., "Modeling of NOx and Soot Formation by Eddy Dissipation Concept," International Flame Research Foundation First Topic Oriented Technical Meeting, Amsterdam, The Netherlands, 17-19 Oct. 1989.

17. Bender, R. and Menter, F.R., "Coupling of Large Eddy Simulation with Eddy Dissipation Model," The 5th Framework Programme (1998-2002), Progress Report, ANSYSCFX Ltd.

18. Gupta, R.N., Yos, J.M., Thompson, R.A., "A review of reaction rates and thermodynamic and transport properties for the 11-species air model for chemical and thermal nonequilibrium calculations to 30000K," NASA TM 101528, 1989.

19. http://www.sandia.gov/HiTempThermo/chemkin.html

20. Jones, W.P and Lindstedt, R.P.,"Global reaction schemes for hydrocarbon combustion," Journal of Combustion and Flame, vol. 73, No. 3, 1988, pp. 233-249.

21. Westbrook, C.K. and Dryer, F., "Simplified Reaction Mechanisms for the Oxidation of Hydrocarbon," Journal of Combustion Science and Technology, Vol 27, 1981, pp. 31-43.
22. Nusca, M.J., Kruczynski, D.L "Reacting Flow Simulation for Large-Scale Ram Accelerator," Journal of Propulsion and Power, Vol. 12, No. 1, 1991, pp. 61-69.

23. Nusca, M.J., "Numerical Simulation of the Ram Accelerator Using a New Chemical Kinetics Mechanism," Journal of Propulsion and Power, Vol. 18, No 1, 2002, pp. 44-52.

24. Kovacik, G. J., and Knill, K. J., "Numerical Simulation of Coal Gasification Reactors," International Joint Power Generation Conference \& Exposition, Phoenix, October 36, 1994.

25. Modest, M.F. "Radiative Heat Transfer," Academic Press. 2003

26. Smith, N. S. A., Barlow, R. S., Chen, J.-Y., and Bilger, R. W,"Nitric Oxide Formation in Dilute Hydrogen Jet Flames: Isolation of the Effects of Radiation and TurbulenceChemistry Submodels," Combust. Flame 117:4-31. 1999.

27. Grosshandler, W.L. "RADCAL: A narrow-band model for radiation calculations in a combustion environment," NIST Technical Note 1402, April 1993.

28. ttp://www.ansys.com/products/fluid-dynamics/cfx/

29. Harten, A. "High resolution schemes for hyperbolic conservation laws," Journal of Computational Physics, 135(2):260278, 1997.

30. van Leer, B. "Upwind and high-resolution methods for compressible flow: From donor cell to residual-distribution schemes," Communications in Computational Physics, 1(2):192-205, 2006.

31. Bengherbia, T., Yao Y., Bauer, P.,and Knowlen, C., "Equations of state for 1-D modelling of ram accelerator thrust in thermally choked propulsion mode," Int. J. Engineering Systems Modelling and Simulation, Vol. 2, No. 3, 2010, pp 154-161. 